\title{
Gamma rays induce a p53-independent mitochondrial biogenesis that is counter-regulated by HIF1 $\alpha$
}

\author{
A Bartoletti-Stella ${ }^{1}$, E Mariani ${ }^{1}$, I Kurelac ${ }^{1}$, A Maresca ${ }^{2,3}$, MF Caratozzolo ${ }^{4}$, L lommarini ${ }^{5}$, V Carelli ${ }^{2,3}$, \\ LH Eusebi ${ }^{6}$, A Guido ${ }^{7}$, G Cenacchi ${ }^{8}$, L Fuccio ${ }^{6}$, M Rugolo ${ }^{5}$, A Tullo ${ }^{4}$, AM Porcelli*,5,9 and G Gasparre*,1
}

Mitochondrial biogenesis is an orchestrated process that presides to the regulation of the organelles homeostasis within a cell. We show that $\gamma$-rays, at doses commonly used in the radiation therapy for cancer treatment, induce an increase in mitochondrial mass and function, in response to a genotoxic stress that pushes cells into senescence, in the presence of a functional p53. Although the main effector of the response to $\gamma$-rays is the p53-p21 axis, we demonstrated that mitochondrial biogenesis is only indirectly regulated by $\mathrm{p} 53$, whose activation triggers a murine double minute 2 (MDM2)-mediated hypoxia-inducible factor $1 \alpha$ $(H I F 1 \alpha)$ degradation, leading to the release of peroxisome-proliferator activated receptor gamma co-activator $1 \beta$ inhibition by HIF1 $\alpha$, thus promoting mitochondrial biogenesis. Mimicking hypoxia by HIF1 $\alpha$ stabilization, in fact, blunts the mitochondrial response to $\gamma$-rays as well as the induction of p21-mediated cell senescence, indicating prevalence of the hypoxic over the genotoxic response. Finally, we also show in vivo that post-radiotherapy mitochondrial DNA copy number increase well correlates with lack of HIF1 $\alpha$ increase in the tissue, concluding this may be a useful molecular tool to infer the trigger of a hypoxic response during radiotherapy, which may lead to failure of activation of cell senescence.

Cell Death and Disease (2013) 4, e663; doi:10.1038/cddis.2013.187; published online 13 June 2013

Subject Category: Cancer

Mitochondrial mass and function are controlled through biogenesis of mitochondria, which is pivotal to maintain energetic homeostasis. Peroxisome-proliferator activated receptor gamma co-activators (PGC) preside to such process via a cascade of nuclear proteins that ultimately regulate the balance between the organelles fusion and fission, the replication and transcription of the mitochondrial genome (mtDNA), the assembly and function of the respiratory chain components and the homeostasis of all metabolic enzymes that reside within mitochondria. ${ }^{1-3}$ Such regulation is carried out in a two-way manner and is an integrated pathway that requires a cross-talk between nucleus and mitochondrion, ${ }^{4,5}$ since the latter is a semi-autonomous organelle whose replication appears to be independent from the cell cycle, ${ }^{6-8}$ and may follow its own checkpoints. ${ }^{9}$ Mitochondria are considered as the principal oxygen sensor of the cell, ${ }^{10}$ as one of their main roles is adenosine tri-phosphate (ATP) production via oxidative phosphorylation, which requires $\mathrm{O}_{2}$ as the final acceptor of the electron transfer. Another pivotal oxygen sensor is the master regulator of the hypoxic response, namely hypoxia-inducible factor $1 \alpha(\mathrm{HIF} 1 \alpha)$, a ubiquitous transcription factor that is kept, under normoxia, at often undetectable protein level by continuous degradation via the $26 \mathrm{~S}$ proteasome. ${ }^{11}$ Cross-talk between the two sensors is necessary to shut off oxidative phosphorylation and shift metabolism towards oxygen-independent glycoly$\operatorname{sis}^{12,13}$ in shortage of oxygen. Activation of hypoxia-induced pathways is largely investigated in cancer, where it is thought to strongly contribute to a failure in responding to $\gamma$-radiation therapy. ${ }^{14}$ Gamma rays have been long exploited as an

\footnotetext{
${ }^{1}$ Medical Genetics Unit, Department of Medical and Surgical Sciences (DIMEC), University of Bologna, Bologna, Italy; ${ }^{2}$ Section of Neurology, Neurosurgery and Infantile Neuropsychiatry, Department of Biomedical and NeuroMotor Sciences (DiBiNeM), University of Bologna, Bologna, Italy; ${ }^{3}$ IRCCS 'Istituto delle Scienze Neurologiche', Bologna, Italy; ${ }^{4}$ Institute of Biomedical Technologies (ITB), National Research Council, Bari, Italy; ${ }^{5}$ Department of Pharmacy and Biotechnologies (FABIT), University of Bologna, Bologna, Italy; ${ }^{6}$ Gastroenterology Unit, Department of Medical and Surgical Sciences (DIMEC), University of Bologna, Bologna, Italy; ${ }^{7}$ Radiation Oncology Unit, Department of Medical and Surgical Sciences (DIMEC), University of Bologna, Bologna, Italy; ${ }^{8}$ Section of Pathology, Department of Biomedical and NeuroMotor Sciences (DiBiNeM), University of Bologna, Bologna, Italy and ${ }^{9}$ Health Sciences and Technologies-Interdepartmental Center for Industrial Research, University of Bologna, Bologna, Italy ${ }^{*}$ Corresponding author: G Gasparre, Department of Medical and Surgical Sciences - DIMEC, Medical Genetics Unit-P ad.11, Pol.S.Orsola-Malpighi, via Massarenti 9, 40138 Bologna, Italy. Tel: +39 051 2088430; Fax: +39 051 2088416; E-mail: giuseppe.gasparre @ gmail.com

or A Porcelli, Department of Pharmacy and Biotechnologies - FABIT, via Irnerio 42, 40126 Bologna, Italy. Tel: +39 0512091282 ; Fax: +39 051 242576; E-mail: annamaria.porcelli@unibo.it

Keywords: gamma rays; mitochondrial biogenesis; $\mathrm{p53}$; HIF1 $\alpha$; senescence

Abbreviations: ACT, actin; ATP, adenosine tri-phosphate; BNIP3L, BCL2/adenovirus E1B 19KDa interacting protein 3-like; CDKN1A, cyclin-dependent kinase inhibitor 1A; cDNA, complementary DNA; chx, cycloheximide; Cl, complex I; Cll, complex Il; CS, citrate synthase; DDR, DNA damage response; DFO, desferrioxamine; DMEM, Dulbecco's modified Eagle's medium; DMOG, dimethyloxallylglycine; FACS, fluorescence-activated cell sorter; FBS, fetal bovine serum; Gy, Gray; SDS-PAGE, sodium dodecyl sulphate polyacrylamide gel electrophoresis; HIF1 $\alpha$, hypoxia-inducible factor $1 \alpha$; IR, irradiation; KO, knock-out; LDHA, lactate dehydrogenase A; MDM2, murine double minute 2; mtDNA, mitochondrial DNA; MTR, Mitotracker red; NDRG1, N-myc downstream regulated gene 1; OPA1, optic atrophy 1; PGC, peroxisomeproliferator activated receptor gamma co-activators; PGC-1 $\alpha$, peroxisome-proliferator activated receptor gamma co-activator $1 \alpha$; PHD, prolyl-hydroxylase; RE, responsive element; REC, recovery; S.D., standard deviation; SDHA/B, succinate dehydrogenase subunit A/B; S.E.M., standard error of the mean; TFAM, mitochondrial transcription factor A; UTR, untranslated region; VDAC1, voltage-dependent anion channel 1; vs, versus; X-gal, 5-bromo-4-chloro-3-indolyl- $\beta$-D-galactopyranoside; $\beta$-Gal, beta galactosidase

Received 20.3.13; revised 24.4.13; accepted 06.5.13; Edited by G Raschellá
} 
anticancer strategy due to their ability to cause double-strand breaks within DNA and induce a genotoxic response that locks the cell in a non-replicative state to allow repair. ${ }^{15,16}$ The canonical DNA damage response (DDR) is orchestrated by several protein kinases transducing stress signals, whose activation propagates the damage signal to effector molecules, the most important of which being the tumour suppressor p53. ${ }^{17,18} \mathrm{~N}$-terminal phosphorylated p53 traslocates to the nucleus, escaping a constitutive degradation mediated by the murine double minute human orthologue MDM2. ${ }^{19,20}$ p53 favours replication arrest via, among others, the transcription of cell-cycle regulator cyclin-dependent kinase inhibitor $1 \mathrm{~A}$ (CDKN1A, alias p21). Such p53-p21 axis is one of the major pathways presiding to the trigger of cell senescence, the induction of which represents at the same time the goal and the drawback of anticancer radiotherapy. ${ }^{21}$ In fact, senescent cells are metabolically active yet quiescent, acquire widespread morphological changes and become resistant to apoptosis. Hence, cancer cells in a senescent state might remain as 'dormant' malignant cells, and therefore represent a dangerous potential for tumour relapses, since through disruption of p53 and p21 function they may escape senescence. ${ }^{22,23}$ Nonetheless, radiotherapy is one of the most effective non-surgical treatments of cancer patients with better functional preservation and less systemic influences. ${ }^{24}$ The understanding of the complex interplay between genotoxic and hypoxic responses remains a critical goal to predict therapy outcome. In fact, prevalence of one over the other is thought to determine the fate of cancer cells in response to therapy, while the crossregulation of the mechanisms underlying activation, stabilization, and degradation of p53 and $\mathrm{HIF} 1 \alpha$, and their interaction with MDM2, remain largely to be clarified. ${ }^{25}$ At the same time, identification of molecular markers that may function as predictors of $\gamma$-rays therapy outcome may be useful prognostic tools. In this context, $\gamma$-radiation has been shown to induce an increase in mtDNA copy number in the brain and spleen tissue of mice. ${ }^{26}$ Similarly, X-rays were shown to induce increase in mitochondrial mass and oxidative function under the cell-cycle control, ${ }^{27}$ whereas oncocytic relapses, tumours with an aberrant mitochondrial biogenesis, ${ }^{28}$ were observed to occur post-radiotherapy of colorectal cancers. ${ }^{29,30}$ Overall, these findings point at mitochondrial homeostasis as one of the biological processes most affected by ionizing radiations.

We here investigate the complex mechanistic relationships between p53-genotoxic and HIF1 $\alpha$-hypoxic responses in the regulation of mitochondrial biogenesis and cell senescence following $\gamma$-rays treatment. We demonstrate that $\gamma$-rays strongly induce mitochondrial biogenesis, and that the entity of such process is dependent on a p53-HIF1 $\alpha$ regulated axis that relies on MDM2-mediated HIF1 $\alpha$ degradation. Last, we attempt to translate our findings in vivo and set the basis for the use of mitochondrial parameters to infer efficacy of radiotherapy.

\section{Results}

$\gamma$-Radiation induces a net mitochondrial biogenesis. To test the effect of $\gamma$-rays on mitochondrial biogenesis, we evaluated the mtDNA abundance in irradiated cells. We first analysed TP53 wild-type cells, namely RPE1 and HCT116. As expected, p53 was shown to significantly increase upon radiation treatment, indicating activation of a genotoxic response, which was further confirmed upon increased expression of the p53-dependent p21 (Figure 1a; Supplementary Figure 1A). Both RPE1 and HCT116 cells showed mtDNA copy number increase both at the last day of irradiation (IR) and after $120 \mathrm{~h}$ recovery (REC) in culture (Figure 1b), suggesting that the copy number increase is an ongoing process proceeding beyond stimulus withdrawal. In agreement with the coupling between mtDNA replication and transcription, ${ }^{31}$ the latter was also observed to increase following IR at $120 \mathrm{~h}$ from stimulus withdrawal (Figure 1b). Mitochondrial proteins were also shown to have an increased expression upon IR, consistently with a complete mitochondrial biogenesis activation. In fact, proteins such as the fusion regulator optic atrophy 1 (OPA1) and the mitochondrial transcription factor A (TFAM), involved in mtDNA maintenance and transcription, showed increased expression upon IR and at recovery. The same trend was observed for voltage-dependent anion channel 1 (VDAC1), an indicator of mitochondrial mass. Similarly, expression of mitochondrial respiratory complexes subunits (complex V ATP5 $\beta$, complex II (CII) succinate dehydrogenase subunit A/B (SDHA and SDHB), complex I (CI) NDUFA9 and NDUFS3, and complex III Core II) was shown to increase in response to IR (Figure 1c; Supplementary Figure 1B). Gene expression evaluation of peroxisome-proliferator activated receptor gamma co-activator $1 \beta(\mathrm{PGC}-1 \beta)$, one of the master regulators of mitochondrial biogenesis, indicated a radiation-dependent increase in both RPE1 and HCT116 up to two- and three-fold, respectively (Figure 1d). Expression of PGC-1 $\alpha$, the other biogenesis co-activator, was undetectable in both RPE1 and HCT116, consistently with the knowledge that it is expressed at high levels in tissues where oxidative metabolism is particularly active, such as brown adipose tissue or skeletal muscle. ${ }^{32}$ Concordantly, downstream PGC$1 \beta$ target genes were also shown to be upregulated upon IR (Supplementary Figure 2). These data suggested an overall increase in mitochondrial mass (Figure 1e), which was confirmed by fluorescence-activated cell sorting (FACS) analysis (Supplementary Figure $3 A$ and $B$ ), likely to be driven by a PGC-1 $\beta$ increase. To understand whether this phenomenon was due to a compensatory effect following damage, we evaluated the bioenergetics competence of both cell lines. Following IR, both $\mathrm{Cl}$ - and Cll-driven ATP synthesis were shown to be significantly increased over two-fold in RPE1 and likewise in HCT116 (Figure 1f). The same result was obtained upon evaluation of the activity of citrate synthase (CS), an enzymatic marker of mitochondrial mass (Figure 1f). However, when ATP synthesis and CS activity were normalized over protein content, no changes were observed (Figure 1g), suggesting that the induced mitochondrial biogenesis is more likely due to a coordinated cell and mitochondrial mass increase than to a compensatory mechanism for some radiation-induced mitochondrial damage, and that cells remained metabolically active.

\footnotetext{
$\gamma$-Rays-induced mitochondrial biogenesis is independent on p53. Since PGC-1 $\beta$ appeared to be the main driver of the $\gamma$-rays-induced mitochondrial biogenesis, and following $\gamma$-IR p53 is activated, we sought to determine a potential role
} 

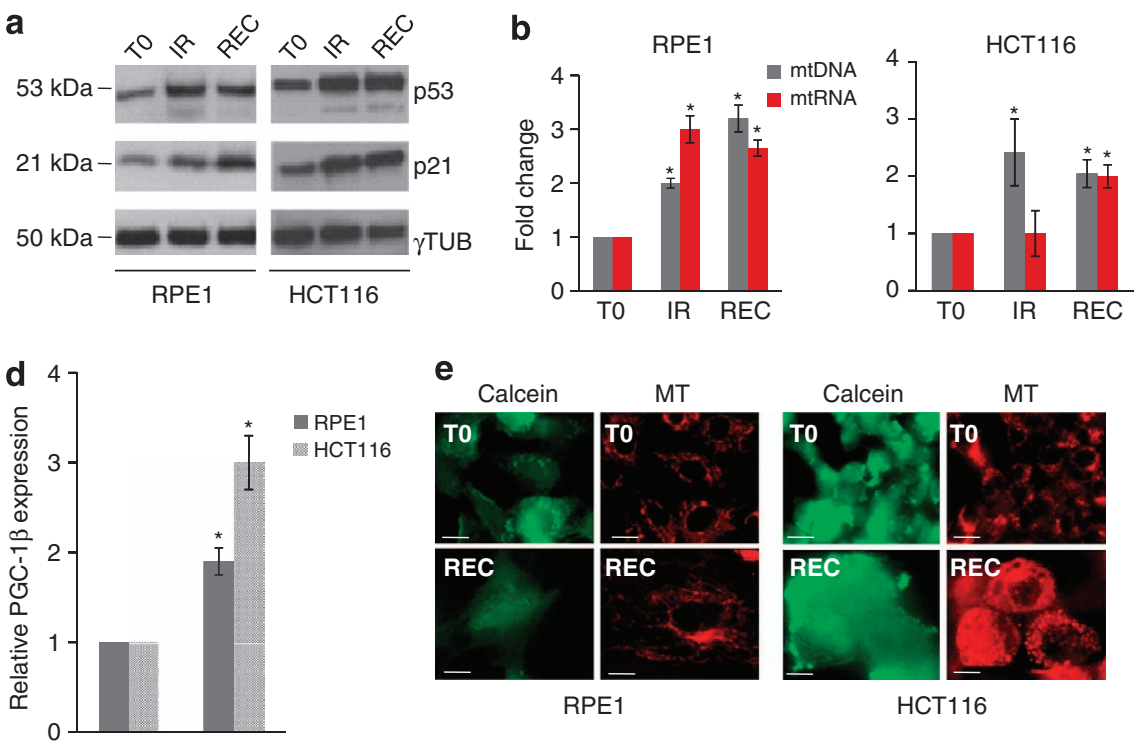

e
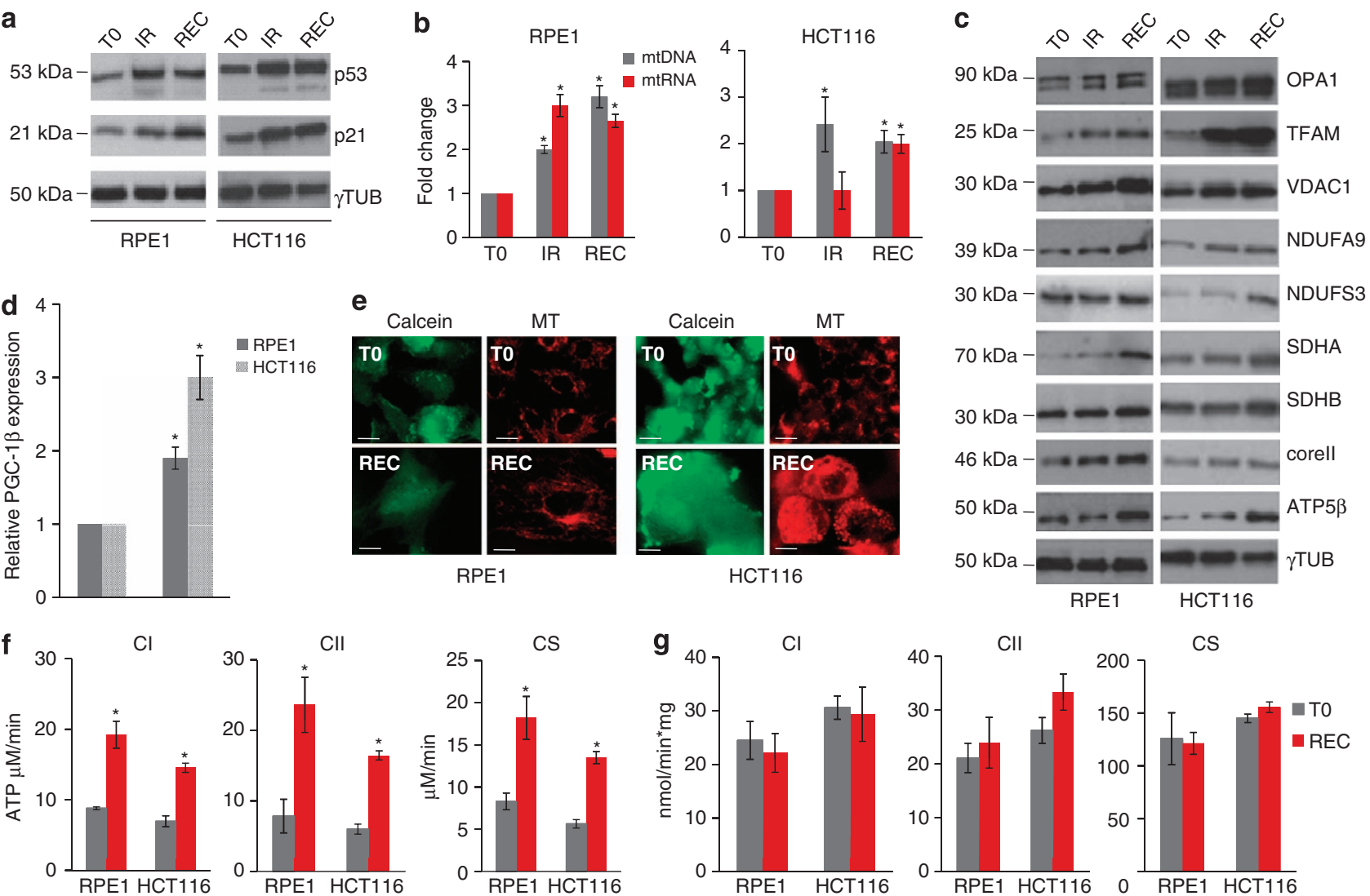

Figure 1 Gamma rays induce mitochondrial biogenesis in RPE1 and HCT116. (a) Western blot analysis of p53 and p21 at the last day of irradiation (IR) and after $120 \mathrm{~h}$ of recovery (REC). Gamma tubulin was used as a loading control. One representative experiment of three is shown. (b) Relative mtDNA copy number and mtRNA transcription. Data are mean \pm S.D. ( $n=3$, ANOVA, ${ }^{*} P<0.05$ versus T0). (c) Western blot analysis of mitochondrial proteins at T0, IR, and REC. (d) Relative mRNA quantification of PGC$1 \beta$ upon IR. Data are mean \pm S.D. ( $n=3$, $t$-test, ${ }^{*} P<0.05$ versus T0). (e) Cells stained with MitoTracker Red (MTR) to evaluate mitochondrial mass and network morphology. Calcein-AM staining was used to highlight cells morphology. One representative experiment of three is shown. Magnification $\times 63 / 1.4$. Length bar corresponds to $25 \mu \mathrm{m}$. (f) The rate of mitochondrial ATP synthesis driven by complex I (Cl) and complex II (CII) substrates, and citrate synthase (CS) activity after irradiation. Data are mean \pm S.D. $\left(n=3\right.$, $t$-test, ${ }^{*} P<0.05$ versus T0). (g) ATP synthesis driven by $\mathrm{Cl}$ and $\mathrm{Cll}$ and $\mathrm{CS}$ activity normalized on protein content. Data are mean \pm S.D. $(n=3)$

for p53 in the phenomena we observed. p53 has been recently shown to display a repressor activity at the promoters of murine $p g c-1 \alpha$ and $-1 \beta$ genes, albeit in the context of telomere dysfunction, so that overexpressed p53 binds its specific responsive elements (REs) to reduce expression of both regulators. ${ }^{33}$ Such an analysis has not been carried out on the orthologue human genes. We looked for specific p53 REs in the promoter of human PGC-1 $\beta$, and detected two close decamers starting at position -2732; - 2706 (GRCh37 - Entrez Gene ID: 133522; Figures 2a and b). We hence took advantage of the syngenic HCT116 cell line knock-out (KO) for TP53, ${ }^{34}$ namely HCT116 ${ }^{\text {TP53KO }}$. Complementation with wild-type p53 (Figure 2c) did not prevent PGC-1 $\beta$ expression increase following IR, similarly to what occurred in mock HCT116 KO cells (Figure $2 \mathrm{~d}$ ). Consistently, p53 was shown not to bind to its PGC-1 $\beta$ weak REs (Figure 2e). p53 activation was confirmed by increase in p21 expression upon $\gamma$-IR (Supplementary Figure 4) and through the binding of $\mathrm{p} 53$ to its REs in the p21 promoter (Figure 2e).

To rule out a potential role for p53 activation in triggering the mitochondrial effects induced by $\gamma$-rays, we evaluated mitochondrial biogenesis parameters in HCT116 ${ }^{\text {TP53KO }}$ and in an osteosarcoma-derived cell line, HPS11, whose TP53 harbours a hemizygous mutation within the DNA binding domain, that is, the c.13055G $>$ C, p.156R $>$ P (Figures $3 a$ and b). Complementation of HCT116 ${ }^{\text {TP53KO }}$ cells with a p.156R $>$ P-mutated p53 confirmed the lack of p21 transactivating ability of such mutant compared with $\mathrm{HCT}_{116^{\mathrm{TP}} 53 \mathrm{KO}}$ complemented with wild-type p53 (Figure 3c), as previously observed. ${ }^{35}$

Both HPS11 and HCT116 ${ }^{\text {TP53KO }}$ were more sensitive to radiation treatment compared with RPE1 and HCT116, not surviving beyond the fourth dose of radiation (Supplementary Figure 5). Nonetheless, both HCT116 ${ }^{\text {TP53KO }}$ and HPS11 displayed a 2.5-fold $\gamma$-rays-induced mtDNA copy number increase, similar to that occurring in RPE1 and HCT116, as well as an increase in mtDNA transcription (Figure 3d). Moreover, levels of PGC-1 $\beta$ transcript and expression of mitochondrial proteins, both structural and belonging to oxidative phosphorylation, were shown to markedly increase upon IR (Figures $3 \mathrm{e}$ and f; Supplementary Figure 6), concordantly with cellular and mitochondrial mass increase (Figures $3 g$ and h; Supplementary Figure $3 C$ ). 


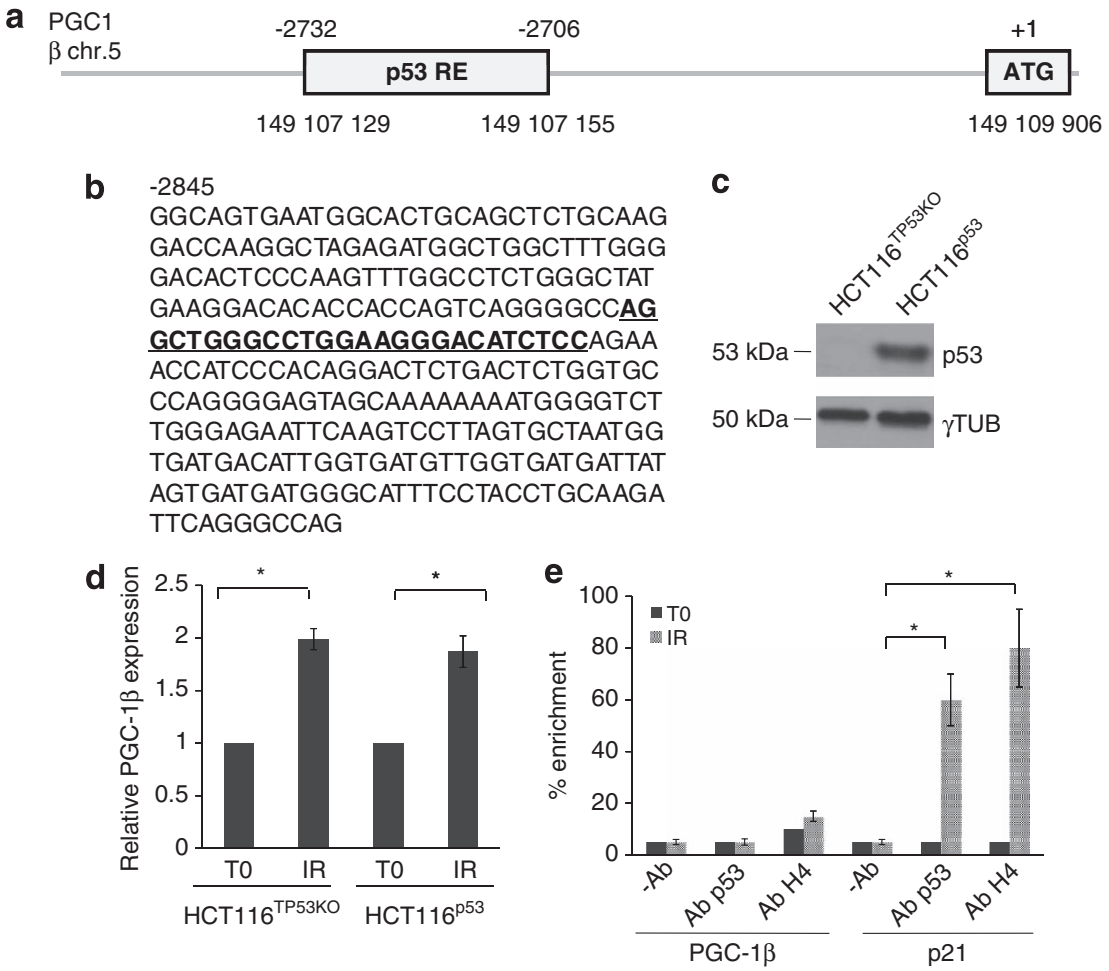

Figure 2 p53 is not a PGC-1 $\beta$ regulator. (a) Schematic representation of the genomic location of the p53-responsive elements (REs) within the promoter region of PGC$1 \beta$. The genomic coordinates are relative to the human genome build hg19. (b) Promoter region of human PGC-1 $\beta$, stretching from -2845 to -2542 with respect to transcription starting site (TSS). The putative p53-RE is underlined. (c) Western blot analysis of p53 after HCT116 ${ }^{\text {TP53KO }}$ complementation with wild-type p53. Gamma tubulin was used as a loading control. One representative experiment of three is shown. (d) Expression of PGC- $1 \beta$ both in HCT116 ${ }^{\mathrm{TP} 53 \mathrm{KO}}$ and in HCT116 $6^{\mathrm{p5} 3}$ upon IR. Data are mean \pm S.D. $\left(n=3\right.$, $t$-test, ${ }^{*} P<0.05$ versus T0). (e) p53 binding and histone H4 acetylation at the promoter of PGC-1 $\beta$ in RPE1 cells upon IR. Data are mean \pm S.D. $(n=2$, $t$-test, $\left.{ }^{*} P<0.05\right)$. The occupancy of p53 and $\mathrm{H} 4$ acetylation at the promoter of $\mathrm{p} 21$ in the same cells is used as positive control

Altogether, these findings point to a lack of involvement of p53 in orchestrating the cell response to $\gamma$-rays in terms of activation of mitochondrial biogenesis.

HIF1 $\alpha$ stabilization blunts $\gamma$-rays-induced mitochondrial biogenesis activation. Next, we sought to determine whether p53 activation may influence effectors that may instead inhibit mitochondrial biogenesis, such as $\mathrm{HIF} 1 \alpha$. In fact, it is well known that genotoxic and hypoxic stress responses are interwoven and tightly regulated by proteins such as MDM2. p53 and HIF1 $\alpha$ may be sequestered or activated, or even led to degradation by MDM2, according to the prevalence of one or the other response. ${ }^{25}$ The relationship between HIF $1 \alpha$ and mitochondrial biogenesis has been previously detailed, especially with respect to its negative PGC- $1 \beta$ regulation via the c-MYC oncogene. ${ }^{36}$ Following IR, HCT116 cells were shown to have a time-dependent HIF $1 \alpha$ protein decrease, which was most profound at recovery (Figure 4a; Supplementary Figure 7A), and therefore antithetically followed p53 protein expression (Figure 1a). Such decrease was a post-transcriptional effect since HIF $1 \alpha$ mRNA was shown to increase at recovery (Figure 4b). Interestingly, an MDM2-dependent HIF1 $\alpha$ degradation has been previously reported. ${ }^{37}$ To validate such a mechanism in the cells analysed, based on the observation that MDM2 also increased following IR (Figure 4c; Supplementary Figure 7B), we overexpressed MDM2 and followed HIF1 $\alpha$ degradation after blocking protein translation with cycloheximide (chx). HIF1 $\alpha$ was shown to be rapidly degraded only when MDM2 was in excess within the cells, even without a radiation stimulus, indicating that a basal MDM2-dependent HIF1 $\alpha$ degradation occurs in HCT116 (Figure 4d; Supplementary Figure 8A). Such degradation did not occur when MDM2 was overexpressed in HCT116 that also overexpressed an $\mathrm{HIF} 1 \alpha$ mutated on the three residues responsible for hydroxylationdependent degradation, ${ }^{38}$ suggesting these residues to be essential (Figure 4e; Supplementary Figure 8B). The necessity for hydroxylases to mediate MDM2-dependent degradation was further confirmed when the potent HIF1 $\alpha$ stabilizer dimethyloxallylglycine (DMOG), a specific inhibitor of prolyl-hydroxylases (PHDs) activity, was used. In such conditions, HIF1 $\alpha$ protein did not decrease upon chx treatment (Figure 4f; Supplementary Figure $8 \mathrm{C}$ ). We hence attempted to force a hypoxic response concomitantly to the genotoxic one, with the aim to reveal whether mitochondrial biogenesis would be activated according to the prevalence of one or the other. DMOG-treated HCT116 cells were shown to retain stabilized $\mathrm{HIF} 1 \alpha$ for the entire duration of the radiation treatment along with increased expression of canonical HIF1 $\alpha$-responsive genes lactate dehydrogenase A ( $L D H A)$ and $\mathrm{BCL} 2$ /adenovirus $\mathrm{E} 1 \mathrm{~B} 19 \mathrm{KDa}$ interacting protein 3-like (BNIP3L) (Supplementary Figure 9), albeit not displaying any increase in mtDNA copy number (Figure 4g). The same finding was obtained when cells were treated with $\mathrm{HIF} 1 \alpha$ 
a

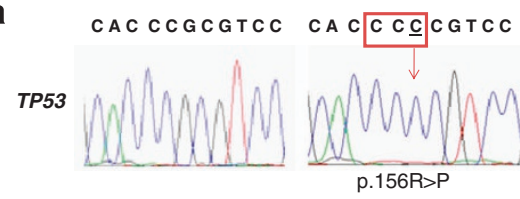

b

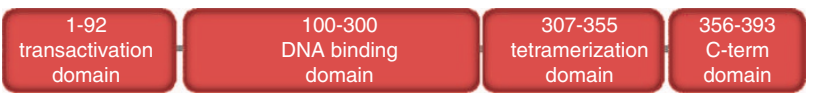

d

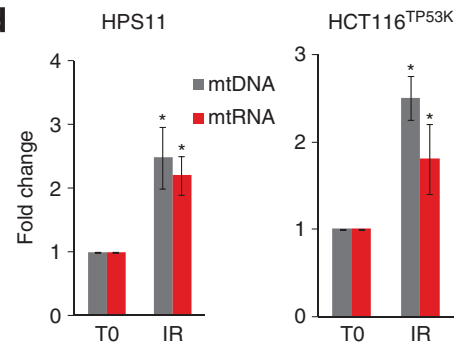

e

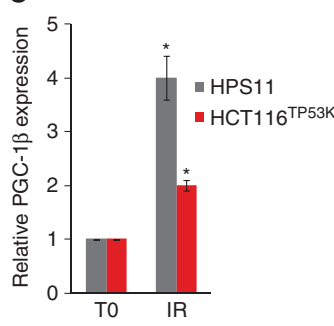

c

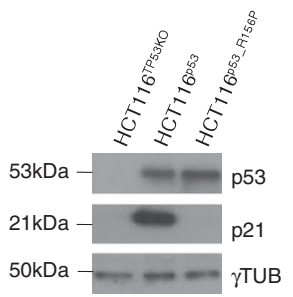

f g

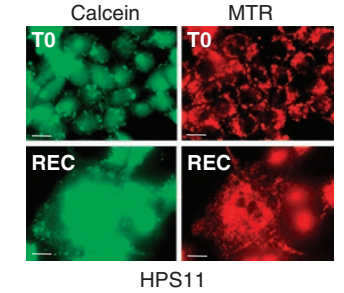

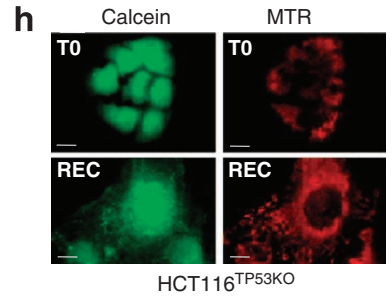

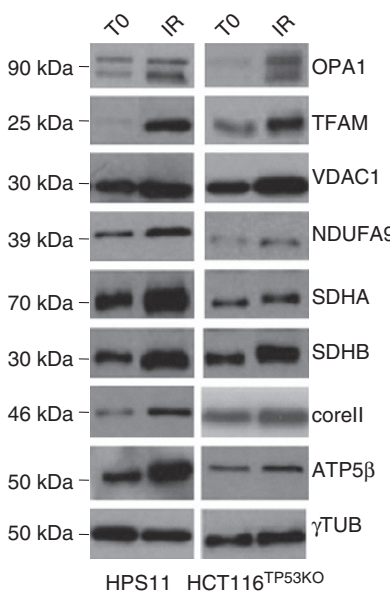

Figure 3 p53 does not directly regulate mitochondrial biogenesis induced by $\gamma$-rays. (a) Electropherograms of the HPS11 cells inactivating TP53 mutation (p.156R $>$ P) within

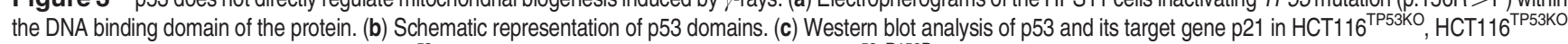

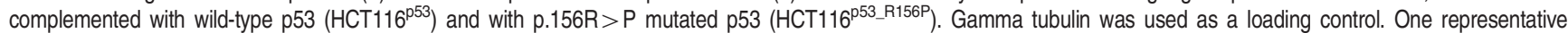
experiment of three is shown. (d) Relative mtDNA copy number and mtRNA transcription, in HPS11 and HCT116 ${ }^{\text {TP53KO }}$ cells upon irradiation (IR). Data are mean \pm S.D. $(n=3$,

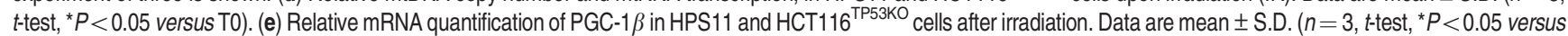
TO). (f) Western blot analysis of mitochondrial proteins upon IR. ( $\mathbf{g}$ and $\mathbf{h}$ ) MitoTracker Red (MTR) and Calcein-AM staining of HPS11 (g) and HCT116 ${ }^{\text {TP53KO }}$ ( $\mathbf{h}$ ) cells to evaluate mitochondrial mass and network morphology prior (T0) and after irradiation (REC). Magnification $\times 63 / 1.4$. Length bar corresponds to $25 \mu \mathrm{m}$

stabilizer desferrioxamine (DFO) (Supplementary Figure 10). Concordantly, neither an increase in $P G C-1 \beta$ expression nor of its target genes (Supplementary Figure 11) after IR was observed in DMOG-treated cells (Figure 4h). Neither mtDNA maintenance proteins nor respiratory complexes subunits were shown to increase after IR in DMOG-treated cells displaying a chronically stabilized $\mathrm{HIF} 1 \alpha$ (Figure 4i; Supplementary Figure 12). Overall, no increase in mitochondrial mass was observed, despite a net cell mass increase (Figure 4j). Analogous findings were obtained when RPE1 cells were treated with DMOG and irradiated (Supplementary Figure 13). Overall, these data indicate that the hypoxic response prevails over the genotoxic one in terms of mitochondrial biogenesis activation that may be induced by IR via an indirect mechanism, namely a re-positioning of MDM2 from p53 to HIF1 $\alpha$. This would foster hydroxylated $\mathrm{HIF} 1 \alpha$ degradation upon p53 activation, preventing HIF $1 \alpha$ to inhibit mitochondrial biogenesis.

HIF1 $\alpha$ prevents radiation-induced cell senescence. We next attempted to investigate whether, along with mitochondrial biogenesis, the hypoxic response would prevail in terms of repressing $\gamma$-rays-induced cell senescence, since this would allow to link the two biological processes.
Mitochondrial biogenesis parameters would then be useful to monitor the efficacy of IR in inducing senescence, which is the main scope of radiotherapy. Interestingly, the stabilization of p53, its main targets p21 and MDM2 did not occur after IR in DMOG-treated RPE1 and HCT116 cells, nor did p16 increase, another senescence effector (Figure 5a; Supplementary Figure 14). The genotoxic stimulus was not able to activate at all p53 in the presence of stabilized HIF $1 \alpha$, as no binding of p53 could be detected on the p21 promoter in DMOG-treated cells, and consequently no $\mathrm{H} 4$ histone acetylation occurred (Figure 5b). Accordingly, the expression of activated p53 gene targets $B A X$ and GADD45A was not shown to increase, indicating the lack of p53 transcriptional activity (Figures $5 \mathrm{c}$ and $\mathrm{d}$ ).

An altered morphology biased towards a cell enlargement, along with the proliferative arrest, but not death, of the cell population following the optimized Gray doses, are clear hallmarks of cell senescence. ${ }^{39,40} \mathrm{HIF} 1 \alpha$ stabilization by DMOG was able to prevent cells to enter senescence, as DMOG-treated cells did not undergo morphological changes and did not show a different beta-galactosidase ( $\beta$-Gal) staining compared with controls after IR (Figures $5 e$ and f). The same effect could be observed when DFO was used (Supplementary Figure 15). Taken together, these data 


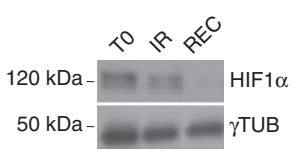

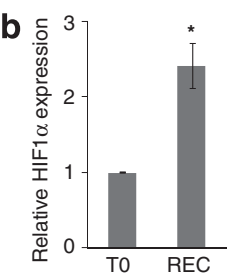

C

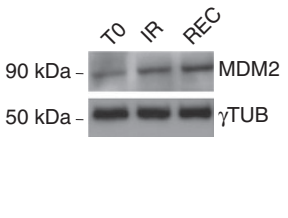

d

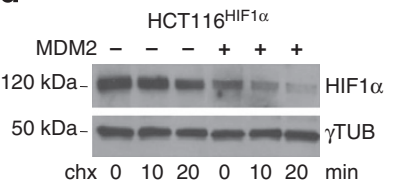

e

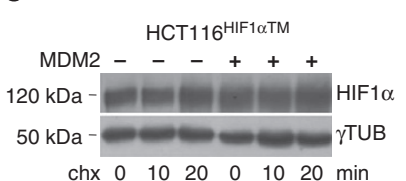

f

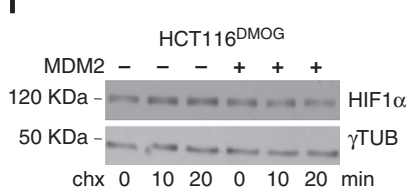

g

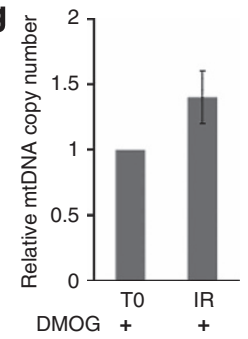

h

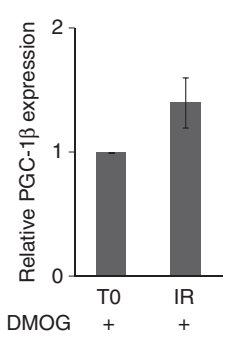

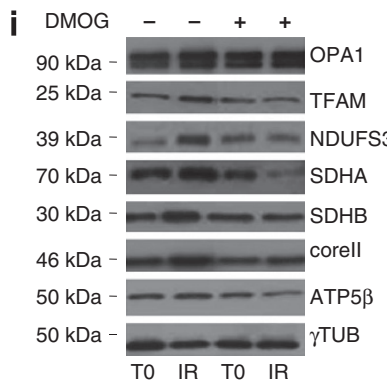

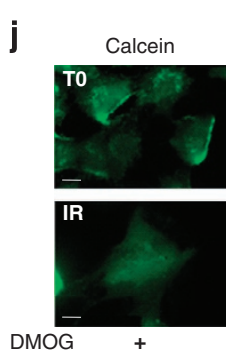

DMOG

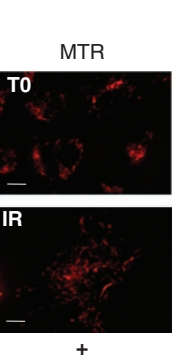

Figure 4 HIF1 $\alpha$ blunts mitochondrial biogenesis induced by $\gamma$-rays. (a) Western blot analysis of HIF1 $\alpha$ in HCT116 cells at irradiation (IR) and after $120 \mathrm{~h}$ of recovery (REC) $\gamma$-tubulin was used as a loading control. One representative experiment of three is shown. (b) Relative expression of HIF $1 \alpha$ in HCT116 cells; data are mean \pm S.D. ( $n=3$, t-test, ${ }^{*} P<0.05$ versus T0). (c) Western blot analysis of MDM2 in HCT116 cells after irradiation; $\gamma$-tubulin was used as a loading control. One representative experiment of three is shown. (d) Western blot analysis of HIF1 $\alpha$ in HCT116 cells overexpressing HIF1 $\alpha$ (HCT116 $\left.{ }^{H I F} 1 \alpha\right)$ upon overexpression of MDM2 $(+)$ compared with clones not overexpressing MDM2 ( - ). Degradation of HIF1 $\alpha$ was evaluated by treating cells with $50 \mu \mathrm{g} / \mathrm{ml}$ of cycloheximide (chx) for 0,10 , and 20 min; $\gamma$-tubulin was used as a loading control. (e) Degradation evaluation of HIF1 $\alpha$ mutated on the three residues subjected to hydroxylation (HIF1 $\alpha$ ), in the presence and absence of overexpressed MDM2. Degradation of HIF1 $\alpha$ was evaluated by treating cells with $50 \mu \mathrm{g} / \mathrm{ml}$ of chx for 0,10 , and $20 \mathrm{~min} ; \gamma$-tubulin was used as a loading control. (f) Degradation evaluation of HIF1 $\alpha$ in the presence and absence of overexpressed MDM2, upon forced pharmacological HIF1 $\alpha$ stabilization by $1 \mu \mathrm{M}$ DMOG. Degradation of HIF1 $\alpha$ was evaluated by treating cells with $50 \mu \mathrm{g} / \mathrm{ml}$ of chx for 0,10 , and $20 \mathrm{~min} ; \gamma$-tubulin was used as a loading control. (g) Relative mtDNA copy number and (h) PGC-1 $\beta$ expression after irradiation in HCT116 cells with stabilized HIF1 $\alpha$ after $1 \mu \mathrm{M} \mathrm{DMOG}$ treatment. Data are mean \pm S.D. $\left(n=3\right.$, $t$-test, ${ }^{*} P<0.05$ versus T0). (i) Western blot analysis of mitochondrial proteins in HCT116 cells treated with DMOG and irradiated. (j) Staining with MitoTracker Red (MTR) and Calcein-AM to evaluate mitochondrial mass and network morphology. Magnification $\times 63 / 1.4$. Length bar corresponds to $25 \mu \mathrm{m}$

indicate that, along with mitochondrial biogenesis, $\mathrm{HIF} 1 \alpha$ stabilization is able to blunt the cell senescence response, suggesting the two processes to be concomitant.

Last, we tested the hypothesis that $\gamma$-rays may trigger mitochondrial biogenesis in vivo and that an easy-to-measure parameter, such as mtDNA copy number, might be predictive of HIF1 $\alpha$ stabilization. We took advantage of a collection of healthy tissue rectal biopsies taken from subjects who had undergone radiation treatment for prostate cancer, since $\gamma$ rays also hit the rectum lining. We evaluated mtDNA copy number in rectal epithelium before IR compared with biopsies taken 2 months after the end of therapy. Surprisingly, mtDNA copy number was shown to be significantly higher in 16/32 $(50 \%)$ subjects (Figure $6 a)$. Considering all data together, the increase was significant over all subjects analysed (pre-IR versus post-IR, $P<0.05$ ), suggesting that the radiation trigger had lasted long after the withdrawal of the stimulus (Figure 6a). A significant inverse correlation was found between decrease in HIF1 $\alpha$ protein and mtDNA copy number increase (Figures $6 \mathrm{~b}$ and c; Fisher's exact test $P=0.039$ ), strengthening the negative relationship between $\operatorname{HIF} 1 \alpha$ stabilization and $\gamma$-ray-induced mitochondrial biogenesis.

\section{Discussion}

In this paper we show that $\gamma$-rays induce a p53-independent net mitochondrial biogenesis blunted by $\mathrm{HIF} 1 \alpha$ stabilization. An increase in mitochondrial mass and function had been previously observed in lung carcinoma cells after exposure to X-rays. ${ }^{27}$ Our results extended such findings to $\gamma$-rays and thoroughly characterized the mitochondrial changes that occur when a genotoxic stimulus is provided. In fact $\gamma$-rays elicit a DDR that, in presence of a functional p53, compels cells to undergo a temporary replicative arrest until repair. ${ }^{15,40}$ One of the critical mediators of such arrest is p21, a transcriptional target of p53, which binds to and inhibits Cdk2/cyclin E complexes, thereby delaying the G1/S phase. ${ }^{41}$ Unsurprisingly, p21 also has a pivotal role in triggering and maintaining cell senescence, the permanent replicative block cells undergo upon entering a quiescent state while remaining metabolically active, which is the main achievement of $\gamma$ radiation when treating cancer. ${ }^{21}$ Despite being regulated mainly through activation of p53, p21 expression appears to be governed also by other factors, such as E2A and N-myc downstream regulated gene 1 (NDRG1), ${ }^{42,43}$ which may 
a TO IR TO IR TO IR TO IR
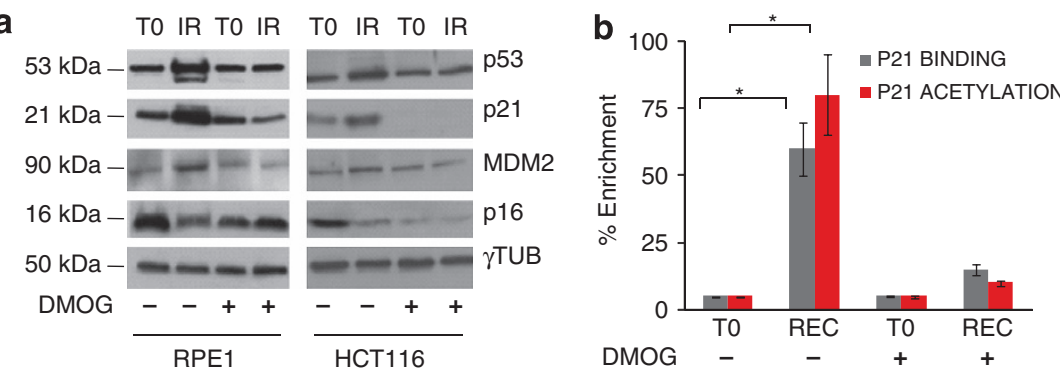

C

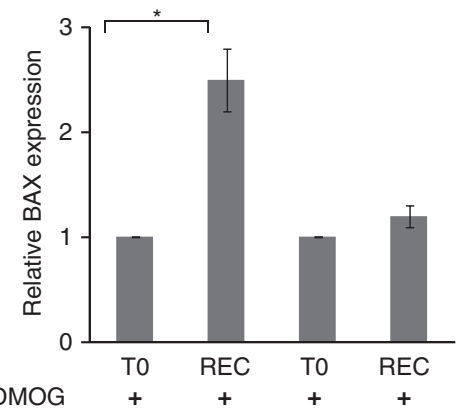

d

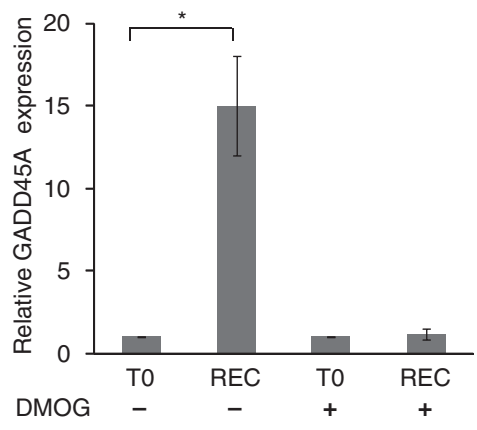

e

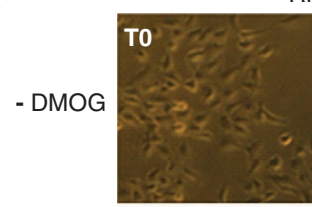

+ DMOG
RPE1

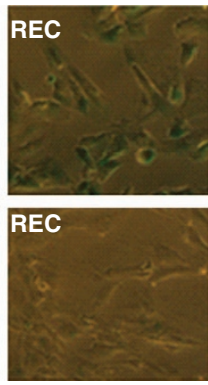

f

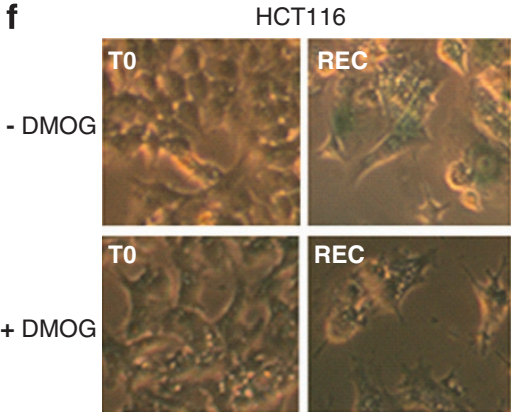

Figure 5 HIF1 $\alpha$ stabilization blunts cells genotoxic response and cell senescence. (a) Western blot analysis of p53, p21, MDM2, and p16 in RPE1 and HCT116 cells in the absence and presence of $1 \mu \mathrm{M} \mathrm{DMOG}$ and irradiated. Gamma tubulin was used as a loading control. One representative experiment of three is shown. (b) p53 occupancy and histone $\mathrm{H} 4$ acetylation at the promoter of p21 in irradiated RPE1 cells, in the presence or absence of stabilized HIF1 $\alpha$ by $1 \mu \mathrm{M}$ DMOG. Data are mean \pm S.D. $(n=2$, $t$-test, ${ }^{*} P<0.05$ versus T0). (c and d) Relative expression of p53-responsive genes $B A X$ and GADD45A in RPE1 cells, in the presence or absence of stabilized HIF1 $\alpha$ by $1 \mu \mathrm{M}$ DMOG, and irradiated. Data are mean \pm S.D. $\left(n=3\right.$, $t$-test, ${ }^{*} P<0.05$ versus T0). (e and f) Senescence-associated $\beta$-galactosidase staining in RPE1 and HCT116 cells in the absence and presence of $1 \mu \mathrm{M} \mathrm{DMOG}$ and irradiated. One representative experiment of three is shown. Magnification $\times 10$

explain p21 expression changes in the absence of p53 activation (Figure 5a).

Replication and function of mitochondria are semi-autonomous processes. Nuclear-encoded proteins are needed for the organelles biogenesis, such as the DNA polymerase gamma or OPA1, yet checkpoints for mtDNA replication, for instance, do not seem to exist or are hypothesized to be different from those of nuclear DNA. ${ }^{9}$ The increase in mitochondrial mass and function we observed in irradiated cells paralleled the cell mass increase that is a hallmark of cell senescence. $^{39}$ Such results find explanation in the semiautonomous replicative mode of mitochondria, which would therefore continue to proliferate despite lack of cell division, in the senescent yet metabolically active G1-arrested cells. The mitochondrial biogenesis increase observed after $\gamma$-rays treatment, therefore, may not be a compensatory effect since mitochondrial function increases in irradiated cells. Albeit the increase in mitochondrial biogenesis appeared independent of p53 activation or even presence, unlike in mice, ${ }^{33}$ the influence of p53 on mitochondrial biogenesis may be indirect, via the known MDM2-mediated HIF1 $\alpha$ degradation, ${ }^{37}$ a hypothesis supported by the increase in MDM2 observed in HCT116 $^{\text {TP53KO }}$ and in HPS11 cells (Supplementary Figure 16). Post-radiation MDM2 increase may hence also occur independently of p53 stabilization, either through other members of the p53 family, such as p73, ${ }^{44}$ or through an $\mathrm{NF} \kappa \mathrm{B}$-mediated induction, ${ }^{45}$ and contribute to HIF1 $\alpha$ degradation and mitochondrial biogenesis increase we observed in p53 KO cells. Both $\mathrm{HIF} 1 \alpha$ and the mitochondrial respiratory chain are considered as the two fundamental oxygen sensors of the cell. As $\mathrm{O}_{2}$ tension decreases, $\mathrm{HIF} 1 \alpha$ stops becoming hydroxylated and is hence stabilized and able to transcribe a large set of genes involved in the regulation of glycolysis and neoangiogenesis. ${ }^{46,47}$ Since $\mathrm{O}_{2}$ is also the major substrate for the electrons of the respiratory chain, the latter is slowed down during hypoxia, and cells must rely on non-oxidative metabolism for ATP production. A basal HIF $1 \alpha$ degradation by MDM2 occurs in cells, ${ }^{37}$ with mechanisms that are likely to be 


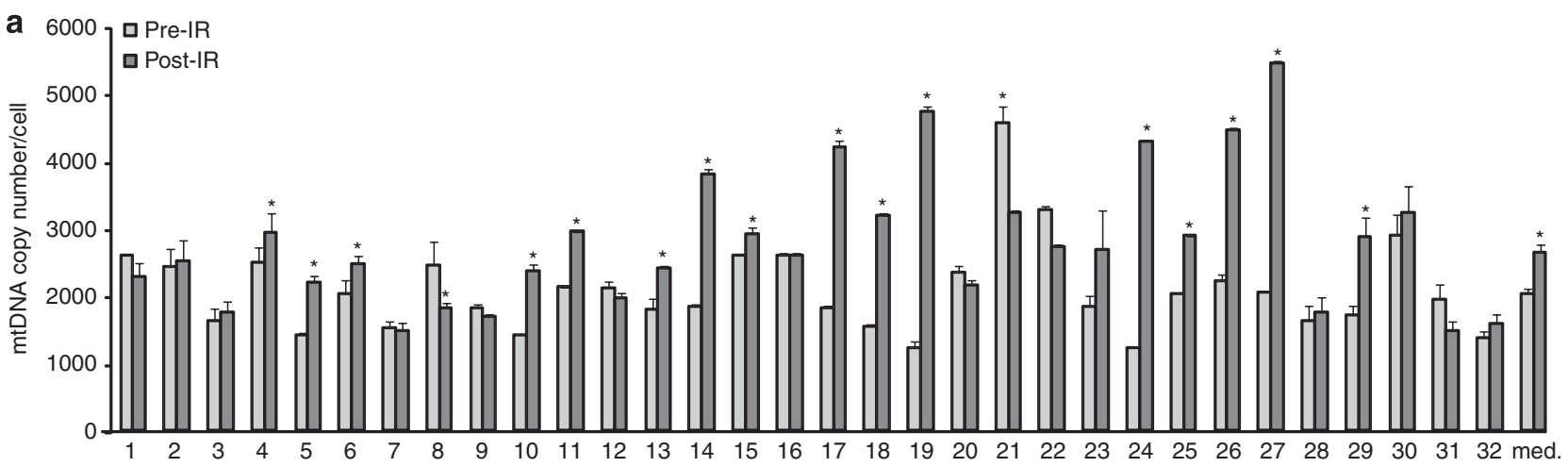

b

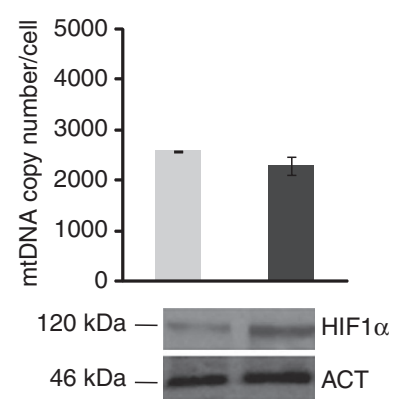

C

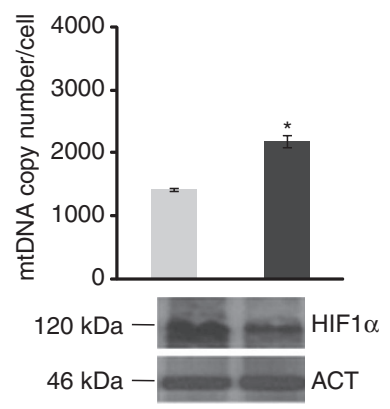

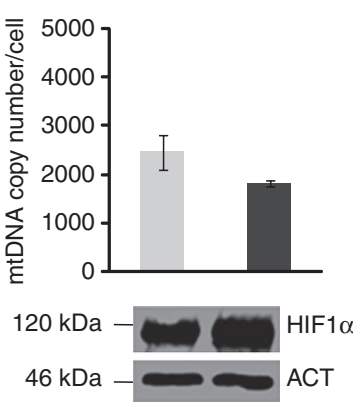

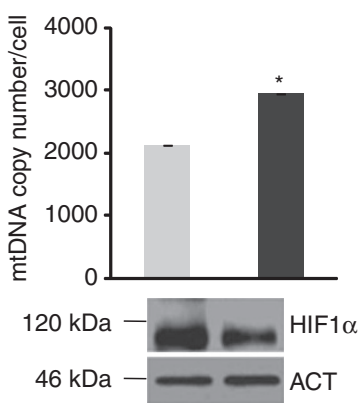

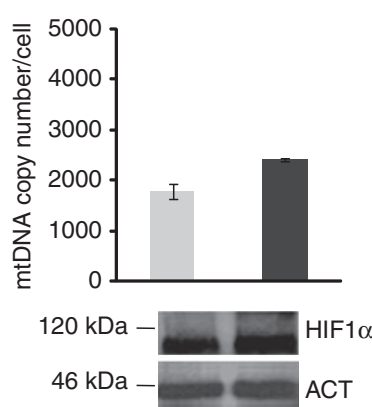
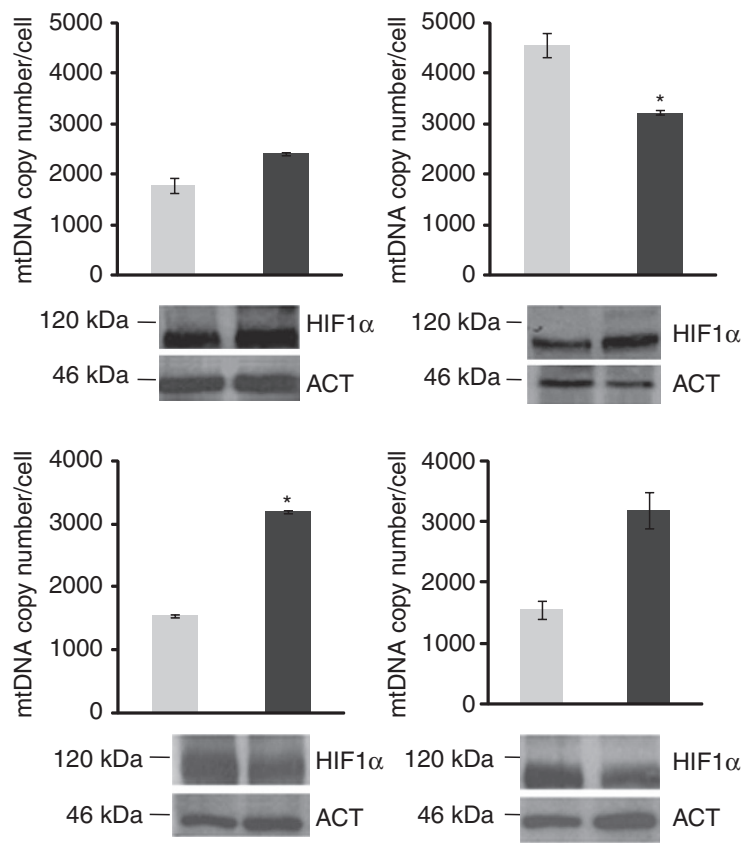

Figure 6 Counter-regulation of HIF1 $\alpha$ expression and mtDNA copy number after radiation treatment in vivo. (a) Absolute mtDNA copy number in rectal biopsies of patients subjected to radiotherapy for prostate carcinoma, prior to (pre-IR) and post-irradiation (post-IR). Data are mean \pm S.E.M. ( ${ }^{*} P<0.05$; paired $t$-test), Wilcoxon Rank tests were used for median comparison of all pre- and post-irradiation biopsies ( ${ }^{*} P<0.05$ versus Pre-IR). (b) Western blot analysis of the expression of HIF1 $\alpha$ in representative cases in which the mtDNA copy number was found not to change or decreased after radiation treatment. (c) Western blot analysis of the expression of HIF1 $\alpha$ in representative cases in which mtDNA copy number increased after radiation treatment. Beta-actin (ACT) was used as a loading control. One representative blot of three is shown. Fisher's exact test was conducted to evaluate significance of the correlation between HIF1 $\alpha$ protein level increase (calculated based on densitometric analysis as a ratio between post-radiation and pre-radiation protein level greater than 1 , in all samples) upon irradiation and lack of mtDNA copy number increase

analogous to the $\mathrm{O}_{2}$-dependent hydroxylation by PHDs, since our mutant HIF1 $\alpha$ stops responding to MDM2 degradation. It is therefore plausible to envision that when p53 is activated upon a genotoxic stimulus, such as $\gamma$-rays, MDM2 may not preside to its degradation and be re-directed towards $\mathrm{HIF} 1 \alpha$, whose degradation would hence be fostered (Figure 7). The relationship between HIF1 $\alpha$ and mitochondrial biogenesis has been previously investigated, given the fact that the two processes are obviously antithetical. It has been shown that $\mathrm{HIF} 1 \alpha$ is an indirect repressor of PGC-1 $\beta$ through a c-MYC-mediated axis, ${ }^{36}$ which overall leads to a downregulation of mitochondrial biogenesis during hypoxia. Our findings therefore point to an indirect control of mitochondrial biogenesis by activated p53, whose role would be to allow MDM2 to degrade HIF1 $\alpha$, with a subsequent release of the basal inhibition by the latter over PGC-1 $\beta$. Our data also shed light on the controversial role of MDM2 in orchestrating the balance between genotoxic and hypoxic response. ${ }^{25,48}$ Although it has been suggested that MDM2 may either degrade or stabilize HIF1 $\alpha$, our results support the former hypothesis, at least upon $\gamma$-rays treatment.

A rather important finding is that when hypoxia is induced in parallel to a genotoxic stimulus, the former response prevails over the latter. In fact, cells treated with DMOG are prevented to undergo senescence when irradiated, as indicated by the unequivocal $\beta$-Gal marker and by the lack of $\mathrm{p} 21$ increase. Interestingly, p53 stabilization also appears to be prevented, likely since non-hydroxylated HIF1 $\alpha$ may not be recognized for degradation by MDM2, which would then re-direct over to p53. Further investigation is warranted to understand in detail why the p53-p21 axis appears to be repressed upon HIF1 $\alpha$ stabilization. In terms of mitochondria, which are the focus of our paper, it is most interesting that the $\gamma$-rays-induced 


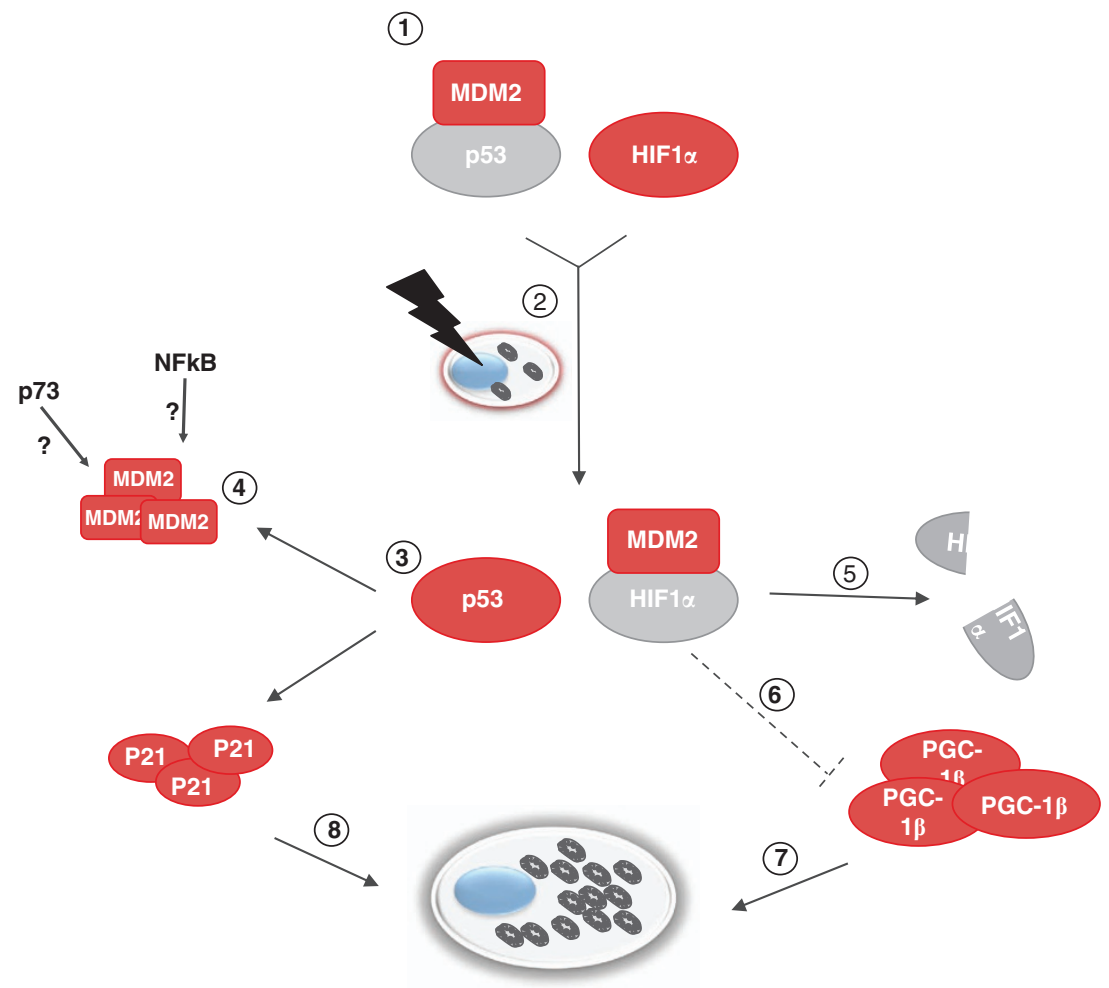

Figure 7 Schematic representation of the cross-regulation of genotoxic and hypoxic response upon gamma irradiation. Under basal conditions, MDM2 binds and degrades p53 (1). In normoxia, upon gamma radiation stimulus (2), p53 activation promotes the transcription of p21 and MDM2 and allows MDM2 to detach from p53 and redirect over to $\mathrm{HIF} 1 \alpha$ (3). In the absence of $p 53$, the accumulation of MDM2 following gamma radiation may also be due to other factors such as $p 73$ and NF- $k \mathrm{~B}(4)$, however leading to HIF1 $\alpha$ degradation (5). The HIF1 $\alpha$-mediated repression of PGC-1 $\beta$ is therefore inhibited (6), which enables activation of mitochondrial biogenesis (7). Cell senescence triggered by the activated p53/p21 axis (8), may instead not occur under hypoxia, when HIF1 $\alpha$ is stabilized and MDM2 is redirected to p53. Functionally and nonfunctionally active factors are marked in red and grey, respectively

biogenesis is also strongly blunted, in parallel to senescence, during hypoxia. We have managed to show this to occur in vivo as well, 2 months after the withdrawal of the $\gamma$-rays stimulus. Tissues hit by $\gamma$-rays retained a 'scar' of activated mitochondrial biogenesis only when local hypoxia had not set in, as shown by the decreased HIF1 $\alpha$ expression. Whether the lack of a net mitochondrial biogenesis increase is due to a continuous cell replication that does not allow organelles to accumulate, or to a yet unknown and more direct molecular mechanism, biogenesis parallels the activation of cell senescence and contributes to the signalling of an ongoing genotoxic response. In this context, triggering of a hypoxic response may compromise efficacy of $\gamma$-rays in inducing senescence, as we have here shown. Evaluation of mitochondrial biogenesis parameters in vivo, such as mtDNA copy number, may therefore reveal to be an efficient tool to predict the trigger of such a response.

\section{Materials and Methods}

Cell cultures. Human colorectal carcinoma cell line HCT116, their genetically modified derivates lacking TP53, ${ }^{34} \mathrm{HCT} 116^{\text {TP53KO }}$, and the osteosarcoma cell line HPS11 were grown in Dulbecco's Modified Eagle's Medium (DMEM) supplemented with $10 \%$ fetal bovine serum (FBS), $100 \mathrm{units} / \mathrm{ml}$ penicillin, $100 \mu \mathrm{g} / \mathrm{ml}$ G-streptomycin and $2 \mathrm{mmol} / \mathrm{l}$ L-glutamine. Non-tumour immortalized RPE1 (human retinal epithelial) cells were cultured in DF12 medium (DMEM/nutrient mixture F-12 ham; Sigma-Aldrich, Milan, Italy) supplemented with 10\% FBS and 100 units $/ \mathrm{ml}$ penicillin, $100 \mu \mathrm{g} / \mathrm{ml} \mathrm{G}$-streptomycin. Cell lines were maintained in a humidified incubator at $37^{\circ} \mathrm{C}$ with $5 \% \mathrm{CO}_{2}$.

$\gamma$-Rays treatment and HIF1 $\alpha$ compound-mediated stabilization. Treatment was optimized to (i) use $\gamma$-rays doses close to those currently used in radiotherapy, (ii) maintain cells viable (Supplementary Figure 2), and (iii) eliminate dead cells from the population. In all, 200000 cells were seeded per $25 \mathrm{~cm}^{2}$ flask (T0). The following day flasks were submitted to a dose of 4 Gray (Gy), specifically $2 \mathrm{~Gy} / \mathrm{min}$ with the biological irradiator IBL437C (89-294). The treatment was repeated after exactly $24 \mathrm{~h}$ for 4 days (IR). Alternatively, cells were allowed to recovery for $120 \mathrm{~h}$ before harvesting (REC). HIF1 $\alpha$ was stabilized by adding to the culture medium the inhibitor of proline hydroxylase DMOG $(1 \mu \mathrm{M})$ or the iron chelator DFO $(250 \mathrm{nM})$ (Sigma-Aldrich) for the entire duration of the radiation treatment.

Western blotting. Total lysates $(80 \mu \mathrm{g})$ were separated by $10-12 \%$ sodium dodecyl sulphate polyacrylamide gel electrophoresis (SDS-PAGE), and nitrocellulose membranes were incubated with primary antibodies against $\gamma$-tubulin (SigmaAldrich), HIF1 $\alpha$ (Bethyl Laboratories, Montgomery, TX, USA), p53, p21, p16 (Santa Cruz Biotechnologies, Dallas, TX, USA), OPA1 (Bioscience, Oxford, UK), TFAM (AbCam, Cambridge, UK), SDHA, SDHB, NDUFA9, NDUFS3 (MitoSciences, Eugene, OR, USA), ATP5 $\beta$ (BioVision, Milpitas, CA, USA), VDAC (Millipore, Billerica, MA, USA), Core II (Life Technologies, Monza, Italy), and MDM2 (Calbiochem, Billerica, MA, USA). Densitometric analyses were performed with Image J software.

Cellular and mitochondrial morphology. Cellular and mitochondrial morphology was assessed after cell staining with $100 \mathrm{nM}$ calcein-acetoxymethyl ester (calcein-AM, Life Technologies) and $10 \mathrm{nM}$ MitoTracker Red (MTR, Life 
Technologies) for $30 \mathrm{~min}$ at $37^{\circ} \mathrm{C}$. Images were acquired with a digital imaging system using an inverted epifluorescence microscope with $\times 63 / 1.4$ oil objective (Diaphot, Nikon, Japan) and a back-illuminated Photometrics Cascade CCD camera system (Roper Scientific, Tucson, AZ, USA). Images were captured and analysed using the Metamorph software (Universal Imaging Corp., Downingtown, PA, USA).

ATP synthesis evaluation. The rate of mitochondrial ATP synthesis driven by $\mathrm{Cl}$ and $\mathrm{Cll}$ was performed in digitonin-permeabilized cells and normalized on protein content, as previously described. ${ }^{49}$ Briefly, aliquots of cells $(0.1-0.2 \mathrm{mg}$ protein) were incubated with $5 \mathrm{mM}$ malate plus $5 \mathrm{mM}$ pyruvate $(\mathrm{Cl}$ substrates) or with $10 \mathrm{mM}$ succinate (Cll substrate) plus $2 \mu \mathrm{g} / \mathrm{ml}$ rotenone. The reaction was started by addition of $0.2 \mathrm{mM} \mathrm{ADP}$ in the presence of luciferine/luciferase, and chemiluminescence was evaluated as a function of time with a luminometer. After addition of $10 \mathrm{mM}$ oligomycin, the chemiluminescence signal was calibrated with an internal ATP standard. CS activity was determined on an aliquot of permeabilized cells, as previously described. ${ }^{50}$

mtDNA copy number. mtDNA content was evaluated by a Real Time-PCR multiplex assay based on hydrolysis probe chemistry. Primers, probe, and conditions were previously published. ${ }^{51}$ About 2 ng of DNA extracted from cells and tissues was analysed using the LightCycler 480 Probes Master Mix (Roche Diagnostics, Milan, Italy) and the LightCycler 480 (Roche Diagnostics) instrument.

Gene expression analyses via real-time PCR. RNA was extracted from $10^{6}$ cells with TRIZOL reagent (Life Technologies) following manufacturer's instructions. Quantitative real-time PCR (qRT-PCR) for MT-ND5, p21, GADD45A, BAX, PGC-1 $\beta$, HIF1 $\alpha$, POLG, MFN1, MFN2, COX5B, UQCRQ, NDUFB5, and TUBB1 was performed on complementary DNA (CDNA) $(1: 50)$ prepared by retrotranscription of $1 \mu \mathrm{g}$ of total RNA with High Capacity cDNA Reverse Transcription Kit (Life Technologies). The qRT-PCR was performed with GoTaq qPCR Master Mix (Promega, Madison, WI, USA) and run in 7500 Fast Real-Time PCR System (Life Technologies), using following conditions: $95^{\circ} \mathrm{C} 5 \mathrm{~min}$; 45 cycles of $95^{\circ} \mathrm{C} 15 \mathrm{~s}$ and $60^{\circ} \mathrm{C} 45 \mathrm{~s}$. The calculations were performed following $2^{-\Delta \Delta C T}$ method. Primer sequences were designed using Primer3 software. ${ }^{52}$ Primer sequences and concentrations used in the real-time PCR are available on request.

In silico promoter analyses. The promoter and $5^{\prime}$ untranslated region (UTR) regulatory regions of the PGC- $1 \beta$ gene were scanned to verify the presence of one or more p53 REs (p53REs) using the PatSearch algorithm implemented in the DNAfan tool. ${ }^{53,54}$ The syntax pattern of the p53RE is made up of two tandem repeated decamers complying with a specific consensus corresponding to the $5^{\prime}-\mathrm{PuPuPuC}(\mathrm{A} / \mathrm{T})(\mathrm{T} / \mathrm{A})$ GPyPyPy-3' sequence, allowing at most three mismatches. The decamers can be spaced by $0-13 \mathrm{nt}$. The in silico analysis revealed the presence of one p53RE at position $-2732 ;-2706$ (promoter region) upstream the transcription start site (TSS) of the PGC- $1 \beta$ gene (GRCh37 - Entrez Gene ID: 133522).

Chromatin immunoprecipitation. After treatments, proteins were crosslinked to DNA in living nuclei by adding formaldehyde directly to the cell culture medium to a final concentration of $1 \%$. Cross-linking was allowed to proceed for $10 \mathrm{~min}$ at $37^{\circ} \mathrm{C}$. Cells were washed with phosphate-buffered saline, scraped off the plates and resuspended in $20 \mathrm{mM}$ Tris-chloride $\mathrm{pH} 8.3,3 \mathrm{mM} \mathrm{MgCl} 2,20 \mathrm{mM}$ $\mathrm{KCl}$, $1 \mathrm{mM}$ phenylmethylsulphonyl fluoride, $1 \mu \mathrm{g} / \mathrm{ml}$ leupeptin, and $1 \mu \mathrm{g} / \mathrm{ml}$ aprotinin. Nuclei were pelleted by microcentrifugation and lysed by incubation in nuclear lysis buffer (1\% sodium dodecyl sulphate, $10 \mathrm{mM}$ EDTA, $50 \mathrm{mM}$ Trischloride $\mathrm{pH} 8.1,1 \mathrm{mM}$ phenylmethylsulphonyl fluoride, $1 \mu \mathrm{g} / \mathrm{ml}$ leupeptin, and $1 \mu \mathrm{g} / \mathrm{ml}$ aprotinin). The resulting chromatin solution was sonicated to generate 300-1000 bp DNA fragments. After microcentrifugation, the supernatant was diluted with dilution buffer $(0.01 \%$ sodium dodecyl sulphate, $1.1 \%$ Triton $\mathrm{X}-100$, 1.2 mM EDTA, $16.7 \mathrm{mM}$ Tris-chloride $\mathrm{pH} 8.1,167 \mathrm{mM} \mathrm{NaCl}, 1 \mathrm{mM}$ phenylmethylsulphonyl fluoride, $1 \mu \mathrm{g} / \mathrm{ml}$ leupeptin, and $1 \mu \mathrm{g} / \mathrm{ml}$ aprotinin) and precleared with protein A-Agarose/salmon sperm DNA and divided into aliquots. Five micrograms of p53 and HIF1 $\alpha$ antibodies (Santa Cruz, Biotechnologies) or any antibody (as negative control) was added to the chromatin solution and incubated on a rotating platform overnight at $4^{\circ} \mathrm{C}$. In parallel, we added acetylated $\mathrm{H} 4$-histone antibody (Millipore) or any antibody (as negative control) to a small fraction of the chromatin solution. Antibody-protein-DNA complexes were precipitated with protein A-Agarose/salmon sperm DNA. After centrifugation, the beads were washed and the protein-DNA complexes were eluted with $1 \%$ sodium dodecyl sulphate, $100 \mathrm{mM}$ sodium carbonate. DNA-protein crosslinks were reversed by heating at $65^{\circ} \mathrm{C}$ for $4 \mathrm{~h}$ and the DNA was phenol extracted and ethanol precipitated. DNA fragments were analysed by real-time $q-P C R$ using SybrGreen and primers specific for the CDKN1A (p21), as p53 activation-positive control, and PGC-1 $\beta$.

p53 PCR amplification and sequencing. All 10 coding exons of TP53 and exon-intron boundaries of the gene were amplified using Fast Start Taq DNA Polymerase (Roche Diagnostics). PCR amplification was performed in a final volume of $25 \mu \mathrm{l}$ in a 9700 thermal cycler (Life Technologies), and PCR products were purified with Multiscreen PCR clean-up Filter Plates (Millipore). Primer sequences and PCR conditions for all reactions are available on request. Sequencing was performed with BigDye v1.1 (Life Technologies) on both strands according to manufacturer's instructions. Briefly, $0.32 \mu \mathrm{M}$ of primer was used in $10 \mu \mathrm{l}$ final reaction, together with $0.5 \mu \mathrm{l}$ of BigDyev1.1 and $2 \mu \mathrm{l}$ of Buffer $(2 \times)$. Upon cycling (4-min elongation) the amplicons were precipitated and run in an ABI3730 Genetic Analyzer automated sequencing machine (Life Technologies). Electropherograms were analysed using Chromas Lite v.2.01 (Technelysium, South Brisbane, QLD, Australia).

TP53, MDM2, HIF1 $\alpha$, and HIF1 $\alpha$ cloning, transfection, and degradation evaluation. TP53, MDM2, and HIF1 $\alpha$ full-length CDNAs were cloned into pcDNA3.1-vector (Life Technologies). To generate a form of HIF1 $\alpha$ that is not subjected to hydroxylases degradation, $\mathrm{HIF} 1 \alpha$, and is constitutively active, amino acids P402, P564, and P803 of HIF1 $\alpha$ were replaced with alanine residues using QuikChange Site-Directed Mutagenesis Kits (Agilent, Santa Clara, CA, USA). Cells were transfected using X-tremeGENE HP DNA Transfection Reagent (Roche Diagnostics), as described by the manufacturer. Mutagenesis primers are available on request. Treatments with chx $(50 \mu \mathrm{g} / \mathrm{ml})$ were performed at $24 \mathrm{~h}$ after MDM2 transfection and cells collected after 0,10 , and $20 \mathrm{~min}$ of incubation.

Senescence-associated $\boldsymbol{\beta}$-Gal assay. Increase in endogenous $\beta$-Gal activity at higher $\mathrm{pH}$ than optimal are unequivocal markers of the switch towards a senescent phenotype. ${ }^{55}$ Increased $\beta$-Gal activity was determined as previously described. ${ }^{55}$ The assay was performed on irradiated cells after recovery. Cells were washed twice with PBS and then incubated for $7 \mathrm{~min}$ with a fixation solution ( $2 \%$ formaldehyde and $0.2 \%$ glutaraldehyde in PBS). Cells were washed five times with PBS and incubated with a staining solution $(40 \mathrm{mM}$ citric acid/Na phosphate buffer $\mathrm{pH} 6,1 \mathrm{mg} / \mathrm{ml} \mathrm{X}$-gal, $5 \mathrm{mM} \mathrm{K}_{4}\left[\mathrm{Fe}(\mathrm{CN})_{6}\right] 3 \mathrm{H}_{2} \mathrm{O}, 5 \mathrm{mM} \mathrm{K} \mathrm{K}_{3}\left[\mathrm{Fe}(\mathrm{CN})_{6}\right], 150 \mathrm{mM}$ $\mathrm{NaCl}$ and $1 \mathrm{mM} \mathrm{MgCl}_{2}$ in $\mathrm{ddH}_{2} \mathrm{O}$ ) at $37^{\circ} \mathrm{C}$ until $\beta$-Gal staining became visible. Cells were finally washed five times with PBS.

Rectal biopsies collection. The study included 32 male patients, 18 years of age and older with prostate cancer. All patients underwent three-dimensional conformal radiotherapy and, by using 4-5-field techniques, a minimum energy of $6 \mathrm{MV}$ was applied on linear accelerators. A computed tomography scan was performed before radiotherapy to enhance the reliability of the rectal dose-volume histogram. Dosing schedules followed the institutional protocols. During the treatment, patients laid in the supine position and were immobilized at the pelvis. Over 6- to 7-week period, using daily fractionation of 2 Gy for 5 days a week, patients received a total dose of external-beam radiation ranging from 66 to $74 \mathrm{~Gy}$, given in 33-37 fractions. The radiation dose was prescribed to the isocentre. ${ }^{56}$ During the examination by rectosigmoidoscopy, bioptic sampling was performed from the anterior wall of the rectum, $10 \mathrm{~cm}$ above the anal verge, before and 1 month after the radiotherapy. Samples were snap frozen and kept at $-80^{\circ} \mathrm{C}$ until the molecular analysis was performed. Patients were enrolled following internal ethical committee procedures.

Statistical analysis. Student's $t$-test was used for comparing two groups; ANOVA test was used for comparing more than two groups. Paired $t$-test was used for comparing the mtDNA copy number in pre- and post-IR single biopsies and Wilcoxon Rank tests were used for median comparison of all pre- and post-IR biopsies. $P$-value $<0.05$ was considered for any statistically significant association.

\section{Conflict of Interest}

The authors declare no conflict of interest. 
Acknowledgements. This work was supported by Associazione Italiana Ricerca sul Cancro (AIRC) IG8810; by the Italian Ministry of University (MIUR) gran PRIN2008 to AMP and Futuro in Ricerca 'TRANSMIT' to GG; by grant DISCO TRIP - Fondazione Umberto Veronesi to GG; IK is supported by a triennial AIRC fellowship 'Borromeo'. LI is supported by an annual fellowship 'Young Investigator Programme 2012-2013' by Fondazione Umberto Veronesi. We thank Dr. M Voltattorni and V Del Dotto for technical help.

1. Lelliott CJ, Medina-Gomez G, Petrovic N, Kis A, Feldmann HM, Bjursell M et al. Ablation of PGC-1beta results in defective mitochondrial activity, thermogenesis, hepatic function, and cardiac performance. PLOS Biol 2006; 4: e369.

2. Liesa M, Borda-d'Agua B, Medina-Gomez G, Lelliott CJ, Paz JC, Rojo M et al. Mitochondrial fusion is increased by the nuclear coactivator PGC-1beta. PLOS ONE 2008; 3: e3613.

3. Scarpulla RC. Metabolic control of mitochondrial biogenesis through the PGC-1 family regulatory network. Biochim Biophys Acta 2011; 1813: 1269-1278.

4. Liu Z, Butow RA. Mitochondrial retrograde signaling. Annu Rev Genet 2006; 40: 159-185.

5. Scarpulla RC. Transcriptional paradigms in mammalian mitochondrial biogenesis and function. Physiol Rev 2008; 88: 611-638.

6. Falkenberg M, Larsson NG, Gustafsson CM. DNA replication and transcription in mammalian mitochondria. Annu Rev Biochem 2007; 76: 679-699.

7. Ryan MT, Hoogenraad NJ. Mitochondrial-nuclear communications. Annu Rev Biochem 2007; 76: 701-722.

8. Magnusson J, Orth M, Lestienne P, Taanman JW. Replication of mitochondrial DNA occurs throughout the mitochondria of cultured human cells. Exp Cell Res 2003; 289: 133-142.

9. Singh KK. Mitochondria damage checkpoint, aging, and cancer. Ann NY Acad Sci 2006 1067: 182-190.

10. Wallace DC. A mitochondrial paradigm of metabolic and degenerative diseases, aging, and cancer: a dawn for evolutionary medicine. Annu Rev Genet 2005; 39: 359-407.

11. Semenza GL. Regulation of oxygen homeostasis by hypoxia-inducible factor 1. Physiology (Bethesda) 2009; 24: 97-106.

12. Semenza GL. Oxygen-dependent regulation of mitochondrial respiration by hypoxiainducible factor 1. Biochem J 2007; 405: 1-9.

13. Wallace DC. Mitochondria and cancer. Nat Rev Cancer 2012; 12: 685-698.

14. Meijer TW, Kaanders JH, Span PN, Bussink J. Targeting hypoxia, HIF-1, and tumor glucose metabolism to improve radiotherapy efficacy. Clin Cancer Res 2012; 18: 5585-5594.

15. Valerie K, Yacoub A, Hagan MP, Curiel DT, Fisher PB, Grant S et al. Radiation-induced cell signaling: inside-out and outside-in. Mol Cancer Ther 2007; 6: 789-801.

16. Willers H, Dahm-Daphi J, Powell SN. Repair of radiation damage to DNA. Br J Cancer 2004; 90: 1297-1301.

17. Pandita TK, Lieberman HB, Lim DS, Dhar S, Zheng W, Taya $Y$ et al. Ionizing radiation activates the ATM kinase throughout the cell cycle. Oncogene 2000; 19: 1386-1391.

18. Reinhardt HC, Schumacher B. The p53 network: cellular and systemic DNA damage responses in aging and cancer. Trends Genet 2012; 28: 128-136.

19. Shieh SY, Ikeda M, Taya Y, Prives C. DNA damage-induced phosphorylation of p53 alleviates inhibition by MDM2. Cell 1997; 91: 325-334.

20. Xu Y. Regulation of p53 responses by post-translational modifications. Cell Death Diffe 2003; 10: 400-403.

21. Nardella C, Clohessy JG, Alimonti A, Pandolfi PP. Pro-senescence therapy for cancer treatment. Nat Rev Cancer 2011; 11: 503-511.

22. Beausejour CM, Krtolica A, Galimi F, Narita M, Lowe SW, Yaswen P et al. Reversal of human cellular senescence: roles of the p53 and p16 pathways. EMBO J 2003; 22: 4212-4222.

23. Brown JP, Wei W, Sedivy JM. Bypass of senescence after disruption of p21CIP1/WAF1 gene in normal diploid human fibroblasts. Science 1997; 277: 831-834.

24. Kim JJ, Tannock IF. Repopulation of cancer cells during therapy: an important cause of treatment failure. Nat Rev Cancer 2005; 5: 516-525.

25. Sermeus A, Michiels C. Reciprocal influence of the p53 and the hypoxic pathways. Cell Death Dis 2011; 2: e164.

26. Malakhova L, Bezlepkin VG, Antipova V, Ushakova T, Fomenko L, Sirota N et al. The increase in mitochondrial DNA copy number in the tissues of gamma-irradiated mice. Cell Mol Biol Lett 2005; 10: 721-732.

27. Yamamori T, Yasui $\mathrm{H}$, Yamazumi M, Wada $\mathrm{Y}$, Nakamura $\mathrm{Y}$, Nakamura $\mathrm{H}$ et al. Ionizing radiation induces mitochondrial reactive oxygen species production accompanied by upregulation of mitochondrial electron transport chain function and mitochondrial conten under control of the cell cycle checkpoint. Free Radic Biol Med 2012; 53: 260-270.

28. Gasparre G, Bonora E, Tallini G, Romeo G. Molecular features of thyroid oncocytic tumors. Mol Cell Endocrinol 2010; 321: 67-76.

29. Ambrosini-Spaltro A, Salvi F, Betts CM, Frezza GP, Piemontese A, Del Prete P et at. Oncocytic modifications in rectal adenocarcinomas after radio and chemotherapy. Virchows Arch 2006; 448: 442-448.
30. Rouzbahman M, Serra S, Chetty R. Rectal adenocarcinoma with oncocytic features: possible relationship with preoperative chemoradiotherapy. J Clin Pathol 2006; 59: 1039-1043.

31. Bonawitz ND, Clayton DA, Shadel GS. Initiation and beyond: multiple functions of the human mitochondrial transcription machinery. Mol Cell 2006; 24: 813-825.

32. Puigserver P, Wu Z, Park CW, Graves R, Wright M, Spiegelman BM. A cold-inducible coactivator of nuclear receptors linked to adaptive thermogenesis. Cell 1998; 92: 829-839.

33. Sahin E, Colla S, Liesa M, Moslehi J, Muller FL, Guo M et al. Telomere dysfunction induces metabolic and mitochondrial compromise. Nature 2011; 470: 359-365.

34. Bunz F, Dutriaux A, Lengauer C, Waldman T, Zhou S, Brown JP et al. Requirement for p53 and p21 to sustain G2 arrest after DNA damage. Science 1998; 282: 1497-1501.

35. Youlyouz-Marfak I, Gachard N, Le Clorennec C, Najjar I, Baran-Marszak F, Reminieras L et al. Identification of a novel p53-dependent activation pathway of STAT1 by antitumour genotoxic agents. Cell Death Differ 2008; 15: 376-385.

36. Zhang H, Gao P, Fukuda R, Kumar G, Krishnamachary B, Zeller KI et al. HIF-1 inhibits mitochondrial biogenesis and cellular respiration in $\mathrm{VHL}$-deficient renal cell carcinoma by repression of C-MYC activity. Cancer Cell 2007; 11: 407-420.

37. Ravi R, Mookerjee B, Bhujwalla ZM, Sutter CH, Artemov D, Zeng Q et al. Regulation of tumor angiogenesis by p53-induced degradation of hypoxia-inducible factor 1alpha. Genes Dev 2000; 14: 34-44.

38. Tal R, Shaish A, Bangio L, Peled M, Breitbart E, Harats D. Activation of C-transactivation domain is essential for optimal HIF-1 alpha-mediated transcriptional and angiogenic effects. Microvasc Res 2008; 76: 1-6.

39. Hayflick $L$. The limited in vitro lifetime of human diploid cell strains. Exp Cell Res 1965; 37: 614-636.

40. Rodier F, Campisi J. Four faces of cellular senescence. J Cell Biol 2011; 192: 547-556.

41. Jung $Y S$, Qian $Y, C$ Chen $X$. Examination of the expanding pathways for the regulation of $p 21$ expression and activity. Cell Signal 2010; 22: 1003-1012.

42. Kovacevic Z, Sivagurunathan S, Mangs H, Chikhani S, Zhang D, Richardson DR. The metastasis suppressor, N-myc downstream regulated gene 1 (NDRG1), upregulates p21 via p53-independent mechanisms. Carcinogenesis 2011; 32: 732-740.

43. Prabhu S, Ignatova A, Park ST, Sun XH. Regulation of the expression of cyclin-dependent kinase inhibitor p21 by E2A and Id proteins. Mol Cell Biol 1997; 17: 5888-5896.

44. Davis PK, Dowdy SF. p73. Int J Biochem Cell Biol 2001; 33: 935-939.

45. Busuttil V, Droin N, McCormick L, Bernassola F, Candi E, Melino G et al. NF-kappaB inhibits T-cell activation-induced, p73-dependent cell death by induction of MDM2. Proc Natl Acad Sci USA 2010; 107: 18061-18066.

46. Koh MY, Powis G. Passing the baton: the HIF switch. Trends Biochem Sci2012; 37: 364-372.

47. Semenza GL. Oxygen sensing, homeostasis, and disease. N Engl J Med 2011; 365: 537-547.

48. Chen D, Li M, Luo J, Gu W. Direct interactions between HIF-1 alpha and Mdm2 modulate p53 function. J Biol Chem 2003; 278: 13595-13598.

49. Giorgio V, Petronilli V, Ghelli A, Carelli V, Rugolo M, Lenaz G et al. The effects of idebenone on mitochondrial bioenergetics. Biochim Biophys Acta 2012; 1817: 363-369.

50. Trounce IA, Kim YL, Jun AS, Wallace DC. Assessment of mitochondrial oxidative phosphorylation in patient muscle biopsies, lymphoblasts, and transmitochondrial cell lines. Methods Enzymol 1996; 264: 484-509.

51. Cossarizza A, Riva A, Pinti M, Ammannato S, Fedeli P, Mussini C et al. Increased mitochondrial DNA content in peripheral blood lymphocytes from HIV-infected patients with lipodystrophy. Antivir Ther 2003; 8: 315-321.

52. Rozen S, Skaletsky H. Primer3 on the WWW for general users and for biologist programmers. Methods Mol Biol 2000; 132: 365-386.

53. Gisel A, Panetta M, Grillo G, Licciulli VF, Liuni S, Saccone C et al. DNAfan: a software tool for automated extraction and analysis of user-defined sequence regions. Bioinformatics 2004; 20: 3676-3679

54. Grillo G, Licciulli F, Liuni S, Sbisa E, Pesole G. PatSearch: a program for the detection of patterns and structural motifs in nucleotide sequences. Nucleic Acids Res 2003; 31: 3608-3612.

55. Debacq-Chainiaux F, Erusalimsky JD, Campisi J, Toussaint O. Protocols to detect senescence-associated beta-galactosidase (SA-betagal) activity, a biomarker of senescent cells in culture and in vivo. Nat Protoc 2009: 4: 1798-1806.

56. Fuccio L, Guido A, Laterza L, Eusebi LH, Busutti L, Bunkheila F et al. Randomised clinical trial: preventive treatment with topical rectal beclomethasone dipropionate reduces postradiation risk of bleeding in patients irradiated for prostate cancer. Aliment Pharmacol Ther $2011 ; 34: 628-637$

Cell Death and Disease is an open-access journal

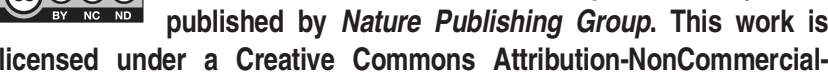
NoDerivs 3.0 Unported License. To view a copy of this license, visit http://creativecommons.org/licenses/by-nc-nd/3.0/ 